\title{
Original
}

\section{Dexamethasone suppression test and negative symptoms of schizophrenics}

\author{
Satoru Shima, Toshinori Kitamura, Yoshikazu Takahashi \\ and Masahiro Asai \\ Department of Neuropsychiatry, School of Medicine, Keio University \\ 35 Shinanomachi, Shinjuku-ku, Tokyo 160, Japan
}

(Received for publication on July 29,1986 )

\begin{abstract}
Of twenty-two female in-patients with DSM-III schizophrenic disorder administered the dexamethasone suppression test, 5 failed to suppress cortisol. A significant positive correlation was obtained between postdexamethasone cortisol levels and the severity of negative symptoms.
\end{abstract}

Key words: cortisol, chronic schizophrenia, depressive symptoms, phenomeno$\log y$

\section{Introduction}

One of the most striking findings in the field of neuroendocrinology is the dexamethasone suppression test (DST), the abnormal response of which is claimed to be a useful biological marker of depressive illness. Carroll et al. ${ }^{1}$ confirmed the diagnostic value of this test for melancholia with a sensitivity of $67 \%$ and a specificity of $96 \%$. However, some studies reported that schizophrenic patients often showed abnormal responses. ${ }^{2-5}$ Dewan et al. ${ }^{2}$ first found that $30 \%$ of 20 male chronic schizophrenics had abnormal DST results. Banki et al..$^{3}$ studied 45 patients with schizophrenic or schizophreniform disorder and found that $19(42 \%)$ showed nonsuppression. They found that the responses to DST were different as regards subtypes; catatonic patients showed nonsuppression frequently, whilst all the paranoid patients suppressed cortisol.

Of interest is the study of Munro et al. ${ }^{4}$ in that $7(31 \%)$ of 23 depressed patients

島 悟, 北村俊則，高檽芳和，浅并昌弘 
with residual schizophrenia failed to suppress cortisol, whilst all of the 23 residual schizophrenics without depression did not. This finding indicates that depressive syndrome superimposed on residual schizophrenia is related to the abnormality of the hypothalamic-pituitary-adrenal axis. A methodological deficit of Munro et al.'s study is, however, that the depressed symptoms were assessed by Carroll Rating Scale for Depression, a self-rating scale with its validity only examined in patients with depression. Schizophrenics may respond differently or idiosyncratically to a self-rating scale. Sawyer et al. ${ }^{5}$ investigated 20 schizophrenics, of which 7 (35\%) were nonsuppressors. In their study 4 of 6 patients with melancholic features, 1 of 8 subjectively depressed patients, and 2 of 6 nondepressed patients showed nonsuppression. Despite the interest paid to the relationship of DST results with the depressive symptoms among chronic schizophrenic patients, there have been no studies concerning the relationship between negative symptoms of schizophrenics and DST results.

The aim of the present study was to clarify the relationship of the DST results with negative symptoms of schizophrenia by applying three observer rating scales; the Brief Psychiatric Rating Scale (BPRS), the 21-item Hamilton Rating Scale for Depression (HRSD), and the Scale for the Assessment of Negative Symptoms (SANS) ${ }^{6}$

\section{Methods}

Twenty-two female schizophrenic in-patients were selected for the study. They were interviewed by using the Schedule for Affective Disorders and Schizophrenia (SADS). The interrater reliability for the Japanese version of SADS was confirmed to be high enough for researches. The diagnosis of schizophrenia was confirmed by applying the criteria of DSM III with the consensus of two raters. Each subject was evaluated on BPRS, HRSD and SANS; the raters were blind to the DST results. We have performed the interrater reliability study of the Japanese version of SANS and found a good $\kappa$ value.

Nineteen nurses were recruited as normal volunteers. Their mean age was 48.8 years (range, 27-61). It was carefully confirmed that they did not meet the medical exclusion criteria proposed by Carroll et al. ${ }^{1}$ DST was performed on these 22 patients and 19 normal volunteers. At 11:00 p.m. $0.5 \mathrm{mg}$ dexamethason was given and blood samples were taken at 4:00 p.m. the following day. Blood cortisol elevels were determined by a radioimmunoassay using anticortisol-21-BSA antiserum; $5 \mu \mathrm{g} / \mathrm{dl}$ or above was considered abnormal suppression. Since among the Japanese population the sensitivity of DST for major depression was found to be raised from $14 \%$ to $37 \%$ when the dexamethasone dose was reduced from $1 \mathrm{mg}$ to $0.5 \mathrm{mg},{ }^{\top}$ the latter was given in this study. All the patients and volunteers gave informed consent prior to the investigation. 


\section{Results}

The subjects' mean age was 45.4 years (range, 25-71), their mean duration of illness 20.5 years (range, 1-56), their mean length of hospitalization 12.3 years (range, 1-28), their mean onset of illness 24.7 years old (range, 11-42), and their mean present daily chlorpromazine equivalent doses of neuroleptics $8447 \mathrm{mg}$ (range, $0-1,700$ $\mathrm{mg}$ ). The mean total BPRS score was 34.6 (range, 20-48), the mean HRSD total score 5.5 (range, 0-20) and the mean SANS summary score (the sum of the global ratings) 16.3 (range, 5-25). Table 1 shows DST results and the psychopathological ratings of the schizophrenics. Of the 22 patients, $5(22.7 \%)$ failed to suppress after dexamethasone loading, whilst $3(15.8 \%)$ of 19 volunteers were nonsuppressors. The frequencies did not differ statistically between the two groups.

A significant positive correlation was found between postdexamethasone cortisol levels and SANS total scores (Spearman rank correlation coefficient, $r=0.487, p<0.05$ ).

Table 1

Postdexamethasone cortisol levels and various psychopathological ratings

\begin{tabular}{cccccclr}
\hline \hline Patient & $\begin{array}{c}\text { Age } \\
\text { (years) }\end{array}$ & $\begin{array}{c}\text { Cortisol } \\
(\mu \mathrm{g} / \mathrm{d} \text { ) }\end{array}$ & $\begin{array}{c}\text { SANS } \\
\text { score }\end{array}$ & $\begin{array}{c}\text { BPRS } \\
\text { score }\end{array}$ & $\begin{array}{c}\text { HRSD } \\
\text { score }\end{array}$ & Subtype & $\begin{array}{r}\text { Dose } \\
(\mathrm{mg})\end{array}$ \\
\hline 1 & 31 & $<2$ & 6 & 31 & 0 & positive & 950 \\
2 & 32 & $<2$ & 6 & 30 & 3 & positive & 650 \\
3 & 47 & $<2$ & 5 & 23 & 3 & mixed & 75 \\
4 & 55 & $<2$ & 12 & 28 & 2 & mixed & 275 \\
5 & 37 & $<2$ & 13 & 36 & 6 & positive & 450 \\
6 & 25 & 2.1 & 15 & 40 & 20 & positive & 750 \\
7 & 41 & 6.8 & 16 & 37 & 3 & negative & 1075 \\
8 & 60 & 3.6 & 23 & 27 & 4 & negative & 337 \\
9 & 40 & 2.1 & 13 & 40 & 6 & positive & 1700 \\
10 & 36 & 2.0 & 25 & 43 & 7 & negative & 650 \\
11 & 44 & 12.8 & 16 & 25 & 0 & negative & 120 \\
12 & 33 & 2.0 & 11 & 37 & 10 & negative & 1300 \\
13 & 34 & $<2$ & 17 & 47 & 11 & mixed & 1075 \\
14 & 48 & 17.8 & 25 & 43 & 3 & negative & 120 \\
15 & 54 & $<2$ & 17 & 34 & 3 & negative & 180 \\
16 & 62 & 6.3 & 23 & 48 & 8 & mixed & 450 \\
17 & 41 & $<2$ & 20 & 42 & 8 & mixed & 600 \\
18 & 54 & $<2$ & 21 & 31 & 2 & negative & 200 \\
19 & 60 & 2.3 & 24 & 35 & 7 & mixed & 300 \\
20 & 52 & 2.3 & 22 & 45 & 4 & mixed & 400 \\
21 & 71 & $<2$ & 15 & 25 & 4 & mixed & 0 \\
22 & 42 & 5.8 & 13 & 20 & 6 & mixed & 150 \\
\hline & & & & & & & \\
\hline
\end{tabular}


We then divided the subjects into three subtypes according to Andreasen et al.'s diagnostic criteria; 5 positive schizophrenics, 8 negative schizophrenics and 9 mixed schizophrenics. All the positive schizophrenics were suppressors, whilst 3 negative schizophrenics and 2 mixed schizophrenics were nonsuppressors. This, however, fell short of statistical significance.

No significant correlations were obtained between postdexamethasone cortisol levels and any of the BPRS total scores, the HRSD total scores, their ages, their durations of illness, their lengths of hospitalization, their ages of onset or their chlorpromazine equivalent doses of neuroleptics.

\section{Discussion}

The results of this study indicate that at least some schizophrenics have the neuroendocrinological abnormality and that the negative symptoms of schizophrenia may relate to this abnormality. In the present study we found no evidence of the neuroleptics' effect on DST results. Nor did we use drugs known to affect DST results such as barbiturates, carbamazepine or high doses of benzodiazepine. Accordingly there may be little need to consider the effect of psychotropic drugs.

The clinical or laboratory characteristics of schizophrenic patients with abnormal DST response are not as yet clear. Caution must be exercised when interpreting Munro et al's claim that depressive symptoms among schizophrenic patients are associated with cortisol nonsuppression, ${ }^{*}$ because only a self-rating scale was adopted to measure depressive symptoms. We therefore applied observer-rating scales to measure the patients' depressive as well as negative symptoms.

In our tudy, $5(23 \%)$ of 22 schizophrenics were found to be nonsuppressors. Whilst the HRSD total scores of all the five nonsuppressors were under 10 and none of them were recognized as clinically depressed, the postdexamethasone cortisol levels were significantly correlated with the SANS total scores and nonsuppressors were all classified as negative schizophrenics. These findings contradict with those of Munro et al. ${ }^{4}$

An explanation for this discrepancy may be that the negative symptoms rated by an observer-rating scale are perceived by the patients themselves cognitively as similar to subjective depressive symptoms and that these psychopathological states are associated with abnormal DST response.

Relevant to this argument are the findings of Levy et al. and Andreasen et al. Levy et al. reported cerebral ventricular enlargement was correlated with suicidal attempts among chronic schizophrenic patients. ${ }^{10}$ Since it was reported that schizophrenics' suicide was associated with depressive state, Levy et al.'s subjects were likely to be depressed. Andreasen et al. showed a preponderance of negative symptoms among schizophrenics with ventricular enlargement and that of positive symptoms among those 
with small ventricles. ${ }^{11}$ It might be therefore speculated that the depressive symptoms of major depression and the negative symptoms of chronic schizophrenia are not so distinctive than usually thought of and they have a mutual neuroendocrinologic marker. Nevertheless the former condition tends to be temporary and reversible whilst the latter might be persistent and irreversible.

This preliminary report may warrant further studies to clarify these interesting issues.

\section{Acknowledgement}

The authors wish to thank Professor N. C. Andreasen, Department of Psychiatry, University of Iowa, for her permission to use the Scale for the Assessment of Negative Symptoms and Professor H. Hosaki, Department of Neuropsychiatry, School of Medicine, Keio University, for his supervision.

\section{References}

1. Carroll, B. J., Feinberg, M., Greden, J. F., Tarika, J., Albala, A. A., Haskett, R. F., James, N. McI., Kronfol, Z., Lohr, N., Steiner, M., de Vigne, J. P. and Young, E.: A specific laboratory test for the diagnosis of melancholia. Arch. Gen. Psychiatry 38: $15-22,1981$

2. Dewan, M. J., Pandurangi, A. K., Boucher, M. L., Levy, B. F. and Major, L. F.: Abnormal dexamethasone suppression test results in chronic schizophrenic patients. Am. J. Psychiatry 139: 1501-1503, 1982

3. Banki, C. M., Arató, M. and Rihmer, Z.: Neuroendocrine differences among subtypes of schizophrenic disorder? Neuropsychobiology 11: 174-177, 1984

4. Munro, J. G., Hardiker, T. M. and Leonard, D. P.: The dexamethasone suppression test in residual schizophrenia with depression. Am. J. Psychiatry 141: 250-252, 1984

5. Sawyer, J. and Jeffries, J. J.: The dexamethasone suppression test in schizophrenia. J. Clin. Psychiatry 45: 399-402, 1984

6. Andreasen, N. C.: Negative symptoms in schizophrenia. Definition and reliability. Arch. Gen. Psychiatry 39: 784-788, 1982

7. Shima, S., Kitamura, T., Shikano, T., Kano, S., Asai, M. and Itoh, H.: Dexamethasone suppression test in affective and other psychiatric disorders. Keio J. Med. 33: 161-165, 1984

8. Davis, J. M.: Comparative doses and costs of antipsychotic medication. Arch. Gen. Psychiatry 33: 858-861, 1976

9. Andreasen, N.C. and Olsen, S.: Negative $v$ positive schizophrenia. Definition and validation. Arch. Gen. Psychiatry 39: 789-794, 1982

10. Levy, A. B., Kurtz, N. and Kling, A. S.: Association between cerebral ventricular enlargement and suicide attempts in chronic schizophrenia. Am. J. Psychiatry 141: 438-439, 1984

11. Andreasen, N. C., Olsen, S. A., Dennert, J. W. and Smith, M. R.: Ventricular enlargement in schizophrenia. Relationship to positive and negative symptoms. Am. J. Psychiatry 139: 297-302, 1982 